\title{
Didactic communication in the training of specialists in aerospace engineering
}

\author{
Mariam Arpentieva*, Peter Menshikov, and Svetlana Braitseva \\ Tsiolkovskiy Kaluga State University, Psychology Department, 248023 Kaluga, Russia
}

\begin{abstract}
The article is devoted to the study of the problems of didactic communication in the training of engineering personnel for the aerospace industry and to the study of the problems of the communication of subjects concerning the training and education of highly qualified engineering personnel for the aerospace industry. In the training of engineering personnel for the aerospace industry the integrated model of didactic communication involves the identification and description of its various components, typical modes of interaction (modes) that reflect different aspects of the person's understanding of the world around him and himself in the process of different types of education and upbringing. Didactic communication in the process of training engineering personnel for the aerospace industry is a multi-level, multi-stage and multi-component phenomenon. The modes, possibilities and limitations of this communication are related to the level and direction of personal, interpersonal and professional development of interaction subjects. The productivity of preparing engineering personnel for the aerospace industry is related to the choice of a model of didactic communication, which is addressed in different ways to the development of cognitive, valuesemantic and meta-cognitive structures that form one or another type of education and upbringing.
\end{abstract}

\section{Introduction}

Didactic communication is the communication of subjects in the process of training and educating engineering personnel for the aerospace industry. It is help to achieve and develop understanding (comprehension) of learning phenomena of the surrounding world and themselves. In the training of personnel for the aerospace industry, didactic communication serves to the solution of educational and cognitive tasks. Didactic communication is also a means of communication, exchange of ideas, experiences between the learner and students in the course of joint activities. It helps to overcome difficulties and barriers in the process of educational and cognitive activity. It helps to activate the establishment of contact with students, provides for their more active involvement in the process of cognition, partnership in the extraction, transfer, processing of educational information [1-7]. Autodidactic communication includes communication about the selflearning of engineering personnel for the aerospace industry, its components and processes.

\footnotetext{
* Corresponding author: mariam rav@mail.ru
} 


\section{Materials and Methods}

The primary method is theoretical integrative analysis. Didactic communication in the process of training engineering personnel for the aerospace industry is a multi-level, multistage and multi-component phenomenon. Its modes, possibilities and limitations are related to the level and direction of personal, interpersonal and professional development of interaction subjects. These characteristics of the development of future specialists as subjects of didactic communication in the educational and professional activities manifest in several field of engineering in the aerospace industry. They manifest in the peculiarities of their understanding of themselves and the world around them, the situations (tasks) of these activities, the development of reflection and information technologies and structures involved in solving problems of professional and educational activities.

\section{Results}

The main features of didactic communication in the process of training engineering personnel for the aerospace industry are related to its modes (orientation): teaching, learning, self-learning (self-teaching), mutual learning (mutual teaching). Didactic communication in its various modes has different capabilities and limitations in the training and development of interaction subjects, in many respects regardless of the subject area or specialization to which the training specialist belongs.

1. Didactic communication in each of the modes is aimed at the formation and development of competence and professionalism, the formation and development of harmonious human relations with oneself and the world. Didactic communication is the key to the success (efficiency and effectiveness) of the activities of teachers and students in the process of training of engineering personnel for the aerospace industry. In each mode, the processes of (re)translation and transformation of knowledge and skills, values and metaknowledge of different subject-professional areas (as components of professional activity) are expressed in varying degrees and specific forms. These processes are realized by means of both similar, general and specific psycho-technologies, which form a certain level and type of the ability to learn and the ability to teach, the ability to educate and the ability to be brought up.

2. Didactic communication in the process of training engineers for the aerospace industry in each of its modes is associated with the primary implementation of certain types of training (for example, "superficial", reproductive, and "deep", creative). The development of didactic communication was determine by the development of values and metacognitive abilities of the subjects of communication. This manifest, among other things, in changes in the understanding of the self and the world around us. This manifested in transformations of the way (type or level) of understanding oneself, the interlocutor, and the situations of educational and teaching activities, world outlook in general. This manifested in the general growth of professional and personal competence, maturity as readiness for productive and harmonious functioning in the sphere of professional and nonprofessional relations. In the preparation of engineering personnel for the aerospace industry, all the marked modes are represent, although in varying degrees. Self-learning and mutual learning (mutual teaching) is a part of the educational process and part of the processes of labor efficiency. Self-learning and mutual learning are increasingly significant. 


\section{Discussion}

In the process of training engineering personnel for the aerospace industry, the development of didactic communication is part of the personal and interpersonal development of communication subjects. This development is connected with the development of values and metacognitive abilities of the subjects of communication. It is reflected in the deepening and expanding understanding of the person and the world around him. It is reflected in changing the type and level of understanding of himself, the interlocutor, the situations of educational and educational activities, the process of education and peace in the world. Autodidactic communication is formed. The "understanding ability" of the individual in relations with himself and with the world develops was strengthen and purse. The dialogue intentions was strengthen and purse too. The interlocutors develop an aspiration for dialogic communication. There is an intensification and realization of dialogical intentions. There is a growing desire for dialogic relations. Didactic communication is presented as an mutual understanding process. It is aimed at the dialogical understanding with a "Significant Other" (such as the teacher or specialist) in the process of training engineering personnel for the aerospace industry. Such communication develops the framework of educational and professional interaction, becoming a dialogue of life-worlds. In the process of training engineering personnel for the aerospace industry a natural change in the modes of didactic communication occurs. This change include the conscious and unconscious accumulation of knowledge and skills, psychotechnologies and values, personal maturation and the professional development of man. In parallel, the modes of instruction are changed. From the first type (passive-reproductive "learning") and the second type (actively-contextual "learning"), the person passes to the third type (selflearning) and the fourth type (dialogic, mutual learning/ mutual teaching).

Each of the types of learning is thus associated with this or that type of didactic communication:

1. Teaching didactic communication assumes that the teaching of young men and women - future engineers in the aerospace industry - is connected with the movement from the learner to the learner. This is an insignificantly realized appropriation of knowledge and skills broadcast by the instructor (teacher). Knowledge and skills in this case are understood with greater or less completeness and depth, not being the subject of care and reflection of subjects of communication. The meta-cognitive aspects of teaching and studying are inactive. Typically, rather unrecognizable appropriation of psycho-technologies, goals and values of activities associated with the appropriated subject-specific (not yet professionalspecific) knowledge and skills; typically unrecognized appropriation of the components of learning activity (the ability to learn). Knowledge and skills of learning activity, values and psycho-technologies, characterized by a general passivity of learning. Within the framework of this mode, to a greater or lesser extent, the surrounding world, its various components, was comprehend. This is a pre-professional stage of formation, in which the ability to learn is partly formed, changing behavior in the process of learning, and "becoming a student" occurs. Understanding is objective, reproductive-ascertaining nature (ascertaining explanations or, in terms of humanistic psychology, "objectively knowing") $[4,6,8]$.

2. Teaching didactic communication assumes that the training of youths and adults, nonprofessionals and professionals is addressed not only to the appropriation of knowledge and skills, but also to change the behavior of the trainee on their basis, the implementation of (quasi-) professional activity. At this level, there is a more or less conscious transfer of knowledge and skills. This knowledge and skills act as a support for the organization and implementation (change) of activities. There is realized (re)translation of values, psychotechnologies and meta-knowledge quasi-professional activities. This mode as a whole is 
relatively unrecognized. Active development of the components of educational, educational and professional activity is typical. An understanding of oneself is realized through an understanding of the educational and professional and professional activities. The requirements of these activities allow us to assess ourselves in its context, determining the measure of compliance with its requirements, its "objective success". This is the initial level of the emergence of professionalism, in which the individual faces the task of changing in accordance with the requirements of activity, developing the ability to learn, that is changing activity and oneself in the learning process. The realizing type of understanding is associated with the predominance of subjective, in many respects subjective, personified explanations, here an empathic-experiential modus (in humanistic psychology, denoted by the term "interpersonal knowledge" - "interpersonal knowing").

3. Didactic communication in the process of self-education (autodidactic communication) involves a qualitative transformation of educational, educational, professional and professional activities in the process of training engineering personnel for the aerospace industry. In this modes come to the fore the more or less conscious, detailed and profound comprehension and transformation of the components of educational, educational, professional and professional activities. This is training to training. There is, therefore, a transformation of the activity of a person educating himself on the basis of skills and habits acquired and transformed by him in the process of development. There is a transformation of his values and goals, psycho-technologies and meta-knowledge of one or another educational, professional and past-professional activity. In the context of this mode, realized, selective mastering of values, psycho-technologies and meta-knowledge (quasi)professional activities. These processes are realized in different ways and ensuring the implementation and qualitative development of activities in general (the transformation of the activity and life activity of the subject). The change in the data of the organization's "supports", the implementation and transformation of activities is associated with the selective search and development of educational and professional knowledge and skills. The specialists are being realized the relatively conscious, detailed (multi-component) and profound reintegration of the knowing and skills. A person begins to understand himself as an inseparable and changing integrity, each component and process significance for himself and the world. Achieving self-understanding is a condition for deep and extensive communication with the world. The ability to learn reaches the status of the ability to change, develop, changing the parameters and technologies of internal and external activities. This is one of the important steps in the way of becoming a person by himself. "Becoming a person", "becoming a professional" mean reaching the state of the selfefficacious and able to teach not only himself but others. These personal levels mean reaching the state to be perfected in the process of self-learning and learning of others (selfefficacy) [4-6]. At the professional level a person chooses the direction of his development, proceeds to a creative rethinking of his professional activity. A type of understanding characteristic of a given level can be designated as an interpretation, less often as a dialog of the experience of experiences (field of experience, emergent, arising in an event and transpersonal cognition) $[1,6]$.

4. Dialogical didactic communication in the process of training of engineering personnel for the aerospace industry is characterized by mutual, in different measure, conscious learning by people of each other. This suggests the ability to change one's own and those of others (life-activity) in the process of exchanging the values of this life exchange of values, psycho-technologies and meta-knowledge, as well as knowledge and skills of interaction. This knowledge and skills were experience, understood by the person as changing. They and their meanings change in relation to activity, and in relation to the reality (world). Learning to learn, life-related changes in life is the leading aspect of the development of the life of the subjects in general. Mutual learning changes the learning of each other as 
individuals, changes their lives in the process of developing awareness (change) of oneself and the world. A person begins to understand himself and the world in an indissoluble unity: as an inseparable and changing integrity, every component and process of internal and external life has equal importance for man and the world. Such a state of "flow" is described as a state of "self-efficacy" (in the behavioral tradition) and as a state of "full functioning" and self-actualization, "becoming a self, partner, professional," "being" or "meeting" (in existential- humanistic psychology) [1, 4, 7].

\section{Conclusions}

A separate kind of didactic communication is mentoring and supervising [5]. Here we are talking about didactic communication in the process of training and retraining of engineering personnel for the aerospace industry in the framework of their own professional activities. In general, such communication, as a rule, can be fragmented and applied to the context of previous modes: in models of learning, learning, self-education, where the weight of metacognitive aspects of teaching and upbringing is most significant.

The transformation of the didactic system includes, thus, the transformation in the process of training engineering personnel for the aerospace industry:

1) the didactic system and its components (changing the type of (re)presentation of knowledge and skills, psycho-technologies and meta-knowledge, changing the values of the didactic system);

2) the ability to learn (transition to a new level of learning, the transformation of values and the psycho-technologies of instruction);

3) professional activity (change of values, psycho-technologies of activity, search and acquisition of knowledge and skills);

4) the personality and its relations with the world, the didactic system as a whole (values, psycho-technologies of learning activity, (meta) knowledge).

\section{References}

1. M. R. Arpentieva, P. V. Menshikov, Didactikticheskaya kommunikastiya: umenie uchit'sya I umenie uchit' [In Russian] (Kaluga: KSU, 2017)

2. P. V. Menshikov, Phenomenon didactikticheskoi kommunikastii [In Russian] (Kaluga: KSU, 2017)

3. P. V. Menshikov, M. R. Arpentieva, Novie obrazovatel'nie praktiki v kontekste kommunikativnogo podhoda [In Russian], Vocational education in the modern world $\mathbf{3}$, 1179 (2017) DOI: 10.15372 / PEMW20170306

4. G. Bateson, The Ecology of Reason [In Russian], (Moscow: Sense, 2000)

5. C. R. Rogers, Freedom to learn (Columbus: Merrill, 1969)

6. C. R. Rogers, Becoming partners (N. Y.: Delacorte Press, 1972)

7. C. R. Rogers, H. C. Lyon, R. Tausch, On Becoming an Effective Teacher (London: Routledge, 2012)

8. H.-J. Bak, \& D.H. Kim, Research in Higher Education 56, 843 (2015) 